\title{
Diabetic $d b / d b$ mice exhibit central nervous system and peripheral molecular alterations as seen in neurological disorders
}

\author{
A Ernst ${ }^{1}$, AN Sharma ${ }^{2}$, KM Elased ${ }^{2}$, PC Guest ${ }^{1}$, H Rahmoune $^{1}$ and S Bahn ${ }^{1,3}$
}

The $d b / d b$ mouse is a widely used preclinical model in diabetes research. Recent studies have shown that these mice also display aspects of psychosis and depression-like behaviors as seen in some psychiatric disorders. Here, we have performed multiplex immunoassay and liquid chromatography mass spectrometry profiling of the plasma and brain samples from $\mathrm{db} / \mathrm{db}$ and control mice to identify altered pathways, which could be related to these behavioral abnormalities. This is the first study to carry out profiling of the brain proteome in this model. Plasma from the $d b / d b$ mice had increased levels of leptin and insulin, decreased levels of peptide YY, glucagon and prolactin and alterations in inflammation-related proteins, compared with control mice. Frontal cortex tissue from the $d b / d b$ mice showed changes in proteins involved in energy metabolism, cellular structure and neural functioning, and the hippocampus had changes in proteins involved in the same pathways, with additional effects on cellular signalling proteins. The overlap of these findings with effects seen in type 2 diabetes, schizophrenia, major depressive disorder and Alzheimer's disease might contribute to a common endophenotype seen in metabolic and neurological disorders. Translational Psychiatry (2013) 3, e263; doi:10.1038/tp.2013.42; published online 28 May 2013

\section{Introduction}

The link between metabolic conditions such as diabetes and psychiatric disorders has been reported widely. ${ }^{1}$ In most cases, metabolic abnormalities have been identified in association with psychiatric disorders as a side effect induced by commonly prescribed anti-psychotic medications. ${ }^{2}$ However, recent studies have shown that such changes can occur at disease onset even before medications have been applied. For example, hyperinsulinemia and insulin resistance have been reported in first onset, antipsychotic naive schizophrenia patients in several studies over the past decade. ${ }^{3,4}$ This indicates that there may be an etiological link between metabolic and psychiatric conditions, which could be an important consideration in downstream treatment approaches.

The $d b / d b$ mouse has been used as a model of type 2 diabetes mellitus and other metabolic conditions, such as obesity and dyslipidemia. ${ }^{5}$ This model was first described in 1965 by Hummel et al., ${ }^{6}$ who identified random mutations in mice associated with obesity and excessive hunger. The models were later segregated as $o b / o b$ mice with gene mutations for leptin, and $\mathrm{db} / \mathrm{db}$ mice that have mutations for the gene encoding the long isoform of the leptin receptor, localized mainly in the hypothalamic region of the brain. ${ }^{7}$ The $d b / d b$ mouse model mirrors the clinical picture of type 2 diabetes mellitus.

A recent study found that hippocampal inflammation in $d b / d b$ mice is associated with increased anxiety-like behavior. ${ }^{8}$ It has been reported that patients with diabetes have an increased probability of developing major depressive disorder ${ }^{9}$ and Alzheimer's disease or cognitive impairments ${ }^{10}$ compared with non-diabetic people. It has also been suggested that type 2 diabetes and Alzheimer's disease share similar biochemical and molecular features. ${ }^{11}$ Consistent with the link between psychiatric and metabolic disorders, recent studies have shown that $d b / d b$ mice exhibit behavioral abnormalities, such as impairments in memory function and long-term potentiation, as well as depression and psychosislike behaviors. ${ }^{12,13}$ Furthermore, treatment of $d b / d b$ mice with anti-diabetic medications such as rosiglitazone has led to improved insulin signalling along with a decrease in measures of depression but not in psychosis-like behaviors. ${ }^{14}$

In this study, we have carried out molecular profiling of plasma samples from $d b / d b$ mice in order to identify peripheral molecular pathways, which are altered in this model. In addition, we have carried out the first proteomic profiling analysis of brain tissues from these mice in order to gain insight into the altered molecular pathways associated with the observed schizophrenia- and depression-like behaviors.

\section{Materials and methods}

Animals. Male $d b / d b$ mice (10-week old; background strain C57BL/KsJ (BKS-Cg-Dock7m + / Leprdb/J)) and age-matched non-diabetic lean control C57BL/KsJ mice (Jackson Laboratories; Bar Harbor, ME, USA) were housed singly in plastic cages with wooden shavings in a temperature controlled room $\left(22-23^{\circ} \mathrm{C}\right)$ on a $12-\mathrm{h} / 12$-h light/dark

\footnotetext{
${ }^{1}$ Department of Chemical Engineering and Biotechnology, University of Cambridge, Cambridge, UK; ${ }^{2}$ Department of Pharmacology and Toxicology, Wright State University, Boonshoft School of Medicine, Dayton, OH, USA and ${ }^{3}$ Department of Neuroscience, Erasmus Medical Centre, Rotterdam, The Netherlands Correspondence: Dr S Bahn or Dr H Rahmoune, Department of Chemical Engineering and Biotechnology, University of Cambridge, Tennis Court Road, Cambridge CB21QT, UK. 
cycle (lights on at 0500 hours) (Table 1). Single housing of $d b / d b$ mice is routinely practiced in our lab and by most of the labs worldwide. Housing at this temperature range results in no change in diurnal rhythm of $d b / d b$ mice compared with control mice. ${ }^{15}$ To assess the metabolic status of the mice, body weight, food consumption and water intake were monitored weekly (Table 2). Blood samples were taken from a cut made on the tip of the tail from each mouse and glucose concentrations were determined using an Accu-Check Advantage Blood Glucose Monitor (Roche Diagnostic Corporation, Indianapolis, IN, USA) to confirm development of diabetes in $d b / d b$ mice compared with that in lean controls. Body fat composition was measured as described previously. ${ }^{13}$ The EchoMRI whole-body composition analyzer (Houston, TX, USA) was used to determine fat and lean body mass. ${ }^{16}$ Fat and lean mass were calculated as percentage of total mass. A total of 20 mice (10 db/db and 10 lean control mice) were killed according to schedule 1, decapitated and trunk blood was collected in ice-chilled tubes containing EDTA and centrifuged at $1100 \mathrm{~g}, 4^{\circ} \mathrm{C}$ for $15 \mathrm{~min}$. Plasma was immediately separated and stored frozen at $-80^{\circ} \mathrm{C}$ for later use. Frontal cortex and hippocampal regions of the brain were dissected on ice and immediately frozen at $-80^{\circ} \mathrm{C}$. All experiments were carried out in full compliance with the principles of laboratory animal care (NIH publication no. 8523, revised 1985), and the protocols were approved by the Wright State University Animal Care and Use Committee.

Plasma insulin measurements. Plasma insulin levels were determined at Mouse Metabolic Phenotyping Centre (Cincinnati, OH, USA) by using the commercial immunoassay kits (Millipore, St Charles, MO, USA) according to the manufacturer's specifications. Briefly, standards, quality controls and samples were incubated for $2 \mathrm{~h}$ in microplate wells pre-coated with mouse anti-rat insulin antibodies $(80 \mu \mathrm{l}$ per well). After washing, biotin-labeled polyclonal antibodies were added ( $100 \mu \mathrm{l}$ per well) followed by incubation for $30 \mathrm{~min}$. After washing, horse radish peroxidase conjugate and the substrate 3,3',5,5'-tetramethylbenzidine solution $(100 \mu \mathrm{l}$ per well) were added for a $15-\mathrm{min}$ incubation. The

Table 1 Physical and metabolic characteristics of $d b / d b$ and control mice

\begin{tabular}{lrc}
\hline Parameter & Control & \multicolumn{1}{c}{$d b / d b$} \\
\hline Age (weeks) & 10 & 10 \\
Body weight $(\mathrm{g})$ & $25.2 \pm 0.6$ & $36.0 \pm 1.2^{*}$ \\
Blood glucose $\left(\mathrm{mg} \mathrm{dl}^{-1}\right)$ & $140.3 \pm 8.8$ & $583.2 \pm 35.9^{*}$ \\
Plasma insulin $\left(\mathrm{ng} \mathrm{ml}^{-1}\right)$ & $1.3 \pm 0.2$ & $4.6 \pm 1.5^{*}$ \\
Percentage of fat mass & $17.9 \pm 1.0$ & $58.9 \pm 0.8^{*}$ \\
Percentage of lean mass & $70.4 \pm 1.0$ & $42.7 \pm 1.4^{*}$ \\
\hline
\end{tabular}

${ }^{\star} P<0.05$ (unpaired $t$-test).

Table 2 Food and water consumption of $d b / d b$ and control mice

\begin{tabular}{lccc}
\hline Mouse strain & $\mathrm{N}$ & $\begin{array}{c}\text { Food intake } \\
\text { (g per day per mouse) }\end{array}$ & $\begin{array}{c}\text { Water intake } \\
\text { (gper day per mouse) }\end{array}$ \\
\hline Lean control & 10 & $3.85 \pm 0.11$ & $9.76 \pm 0.89$ \\
$d b / d b$ & 10 & $6.74 \pm 0.37^{*}$ & $20.15 \pm 2.39^{\star}$ \\
\hline
\end{tabular}

${ }^{\star} P<0.05$ versus lean control mice, unpaired $t$-test. reactions were halted by addition of $100 \mu$ l per well $0.3 \mathrm{~m} \mathrm{HCl}$, and the absorbance of the resulting color product was measured at $\lambda=450 \mathrm{~nm}$. The concentrations of the experimental samples were determined by comparison of the absorbance values with those of a standard curve, constructed using $0.2,0.5,1,2,5$ and $10 \mathrm{ng} \mathrm{ml}^{-1}$ insulin.

Multiplex immunoassay profiling. Plasma samples were analyzed using the RodentMAP, Rat MetabolicMAP and Rat KidneyMAP platforms comprising multiplexed immunoassays for a total of 89 analytes (86 proteins and 3 steroid hormones) (Supplementary Table S1) in a Clinical Laboratory Improved Amendments (CLIA)-certified laboratory at Myriad-RBM (Austin, TX, USA) as described recently. ${ }^{17}$ Immunoassays were calibrated using duplicate standard curves for each analayte and raw intensity measurements converted to protein concentrations using proprietary software. Multiplexed calibrators (eight levels per analyte) and controls (three levels per analyte) are developed to monitor key performance parameters, such as lower limit of quantification, precision, cross-reactivity, linearity, spikerecovery, dynamic range, matrix interference, freeze-thaw stability, and short-term sample stability are established for every assay as described by the manufacturer (http://www. myriadrbm.com/technology/data-quality/). Data analyses were performed using the statistical software package $R$ (http://www.r-project.org) and the levels of analytes were determined. Analyses were conducted under blinded conditions with respect to sample identities, and samples were analyzed in random order to avoid any sequential biases.

Liquid chromatography mass spectrometry (LC-MS ${ }^{\mathrm{E}}$ ) profiling. Frontal cortex and hippocampus tissues from $\mathrm{db} /$ $d b(n=10)$ and control $(n=10)$ mice were sonicated in a buffer comprised of $7 \mathrm{~m}$ urea, $2 \mathrm{~m}$ thiourea, $4 \%$ chaps, $2 \%$ ASB14, $70 \mathrm{~mm}$ dithiothreitol and protease inhibitors (5:1 (v/w) ratio) at a 5:1 (v/w) ratio and mixed for $30 \mathrm{~min}$. Samples were centrifuged for $3 \mathrm{~min}$ at $17000 \mathrm{~g}$ at $4{ }^{\circ} \mathrm{C}$ and the supernatants recovered. Protein concentrations of the lysates were determined using a Bradford assay (Bio-Rad; Hemel Hempstead, UK). Proteins (approximately $100 \mu \mathrm{g}$ ) were precipitated using acetone, centrifuged for $3 \mathrm{~min}$ at $17000 \mathrm{~g}$ at $4{ }^{\circ} \mathrm{C}$ and the pellets suspended in $50 \mathrm{~mm}$ ammonium bicarbonate. Disulfide bonds were reduced in $5 \mathrm{~mm}$ dithiothreitol at $60^{\circ} \mathrm{C}$ for $30 \mathrm{~min}$, and free sulfhydryl groups were alkylated by incubation in $10 \mathrm{~mm}$ iodacetamide in the dark at $37^{\circ} \mathrm{C}$ for $30 \mathrm{~min}$. Protein digestion was conducted using porcine trypsin at a $1: 50(\mathrm{w} / \mathrm{w})$ ratio for $17 \mathrm{~h}$ at $37^{\circ} \mathrm{C}$, and reactions were stopped by addition of $8.8 \mathrm{M} \mathrm{HCl}$ at a 1:60 (w/w) ratio. Quality control samples consisting of frontal cortex and hippocampus protein extracts from a wild-type mouse were prepared as above and underwent all experimental steps in parallel with the test samples to monitor machine performance.

LC-MS ${ }^{\mathrm{E}}$ analyses were carried out in triplicate of individual samples as described previously. ${ }^{18}$ Samples were diluted in $0.1 \%$ formic acid (Sigma-Aldrich; Poole, UK) to a final peptide concentration of $0.12 \mu \mathrm{gl}^{-1}$ and reverse phase LC separation was performed using a nanoACQUITY system (Waters Corporation; Milford, MA, USA) comprised of a C18 trapping 
column $(180 \mu \mathrm{m} \times 20 \mathrm{~mm} ; 5 \mu \mathrm{m}$ particle size $)$ and a C18 BEH nanocolumn $(75 \mu \mathrm{m} \times 200 \mathrm{~mm} ; 1.7 \mathrm{~mm}$ particle size $)$. The buffers were as follows: (A) $\mathrm{H}_{2} \mathrm{O}+0.1 \%$ formic acid and (B) acetonitrile (Sigma-Aldrich) $+0.1 \%$ formic acid. Initial buffer concentrations were 3\% B $(97 \%$ A) followed by 3-30\% B over $90 \mathrm{~min}, 30-90 \%$ B over $25 \mathrm{~min}, 90-97 \%$ B over $5 \mathrm{~min}$, constant $97 \%$ B for $10 \mathrm{~min}$ and $97-3 \%$ B over $1 \mathrm{~min}$. The column was coupled online to a nanoESI emitter on a quadrupole time-of-flight (Q-TOF Premier) mass spectrometer (Waters Corporation). Approximately $500 \mathrm{fmol}^{-1}$ of Glu Fibrinopeptide B (Waters Corporation) was infused every $30 \mathrm{~s}$ using a lock spray for mass calibration. The mass spectrometer was operated in V mode and analyses were performed using positive nanoESI ion mode. The collision energy was $5 \mathrm{eV}$ for low-energy scans and ramped from 17 to $40 \mathrm{eV}$ for high-energy scans with a cycle time of $1.3 \mathrm{~s}$. The low collision energy generates intact precursor ion data, and the high collision energy provides information about the peptide fragments.

Data analysis. Analysis of multiplex immunoassay profiling data was conducted using nonparametric Wilcoxon rank-sum tests to account for any uneven distribution of the data. $P<0.05$ was considered as statistically significant. LC-MS ${ }^{\mathrm{E}}$ data were processed using ProteinLynx Global Server (PLGS) v.2.4 (Waters Corporation) and Rosetta Elucidator v.3.3 (Rosetta Biosoftware; Seattle, WA, USA) for time and mass/charge alignment of ion fragments as described previously. ${ }^{18}$ The Mus musculus complete proteome FASTA (sourced from www.uniprot.org) sequence Integr8 database was used for the appropriate protein searches. Acceptable modifications were set to include oxidation of methionine and phosphorylation of serine, threonine or tyrosine residues. The criteria for valid protein identifications were set at a minimum of three fragment ions/peptide ion and seven fragment ions/protein and detection of peptides in at least two out of three replicates. In addition, proteins had to be identified in $60 \%$ of samples to ensure biological reproducibility. The results were imported into Elucidator for alignment and annotation of the features. The end result was a matrix that included peptide intensities for each sample. Proteins identified by $\geqslant 2$ peptides were considered for further analyses (Supplementary Table S2).

Statistical analyses. Significant differences in protein expression generated by the LC-MS ${ }^{\mathrm{E}}$ analyses, between $d b / d b$ and control mice, were determined using Wilcoxon signed-rank tests $(P<0.05)$. The false discovery rate was calculated, although no adjustments were made for multiple comparisons in order to not exclude possible true positives. Nevertheless, only those molecules with a false discovery rate $<0.4$ and a fold change cut off of 0.10 for the LC-MS ${ }^{\mathrm{E}}$ analyses were applied in order that only those molecules with the most robust changes were considered.

Classification of differentially expressed proteins. The UniProt accession codes of significantly altered proteins found in brain tissues from $d b / d b$ and control mice were uploaded to the Ingenuity Pathway Analysis Knowledge Base (IPKB; Ingenuity Systems; Mountain View, CA, USA).
Networks and pathways that were most significant to the data set were determined by overlaying the uploaded proteins onto predefined pathway maps in the IPKB. A right-tailed Fisher's exact test was used to calculate the $P$-values associated with the identified canonical pathways.

\section{Results}

Plasma analysis. Multiplex immunoassay profiling of plasma samples showed that 31 molecules were present at different levels between $d b / d b$ and control mice (Table 3). As expected, leptin levels were significantly higher (approximately 18-fold) in $d b / d b$ compared with the control mice. Several other molecules were also present at higher levels in the $d b / d b$ mice, including insulin, C-reactive protein, serum amyloid $\mathrm{P}$ component, immunoglobulin $\mathrm{A}$, interleukin 18, monocyte chemotactic proteins 1 and 3 and fibrinogen. In addition, other proteins showed decreased levels in the

Table 3 Multiplexed immunoassay of plasma from $d b / d b$ and control mice

\begin{tabular}{|c|c|c|c|}
\hline Molecule & $\mathrm{P}$-value & Ratio & Function \\
\hline$\Delta$ Leptin & 0.001 & 18.68 & Hormone \\
\hline$\triangle \mathrm{C}$-Reactive protein & 0.001 & 2.59 & Immune response \\
\hline $\begin{array}{l}\text { ASerum amyloid } \mathrm{P} \\
\text { component }\end{array}$ & 0.001 & 2.07 & Immune response \\
\hline$\triangle$ Myeloperoxidase & 0.001 & 1.90 & Enzyme \\
\hline $\begin{array}{l}\text { Plasminogen activator } \\
\text { inhibitor } 1\end{array}$ & 0.002 & 1.82 & $\begin{array}{l}\text { Proteinase } \\
\text { inhibitor }\end{array}$ \\
\hline Almmunoglobulin A & 0.001 & 1.80 & Immune response \\
\hline Interleukin-18 & 0.012 & 1.64 & Immune response \\
\hline Ansulin & 0.002 & 1.63 & Hormone \\
\hline $\begin{array}{l}\text { Monocyte chemotactic } \\
\text { protein } 1\end{array}$ & 0.001 & 1.51 & Immune response \\
\hline $\begin{array}{l}\text { Monocyte chemotactic } \\
\text { protein } 3\end{array}$ & 0.005 & 1.49 & $\begin{array}{l}\text { Immune } \\
\text { Response }\end{array}$ \\
\hline $\begin{array}{l}\text { Matrix Metalloprotei- } \\
\text { nase } 9\end{array}$ & 0.037 & 1.33 & Enzyme \\
\hline$\Delta$ Fibrinogen & 0.042 & 1.23 & Immune response \\
\hline $\begin{array}{l}\Delta \text { Fibroblast growth factor } \\
\text { basic }\end{array}$ & 0.032 & 1.19 & Growth factor \\
\hline $\begin{array}{l}\text { Serum glutamic oxa- } \\
\text { loacetic transaminase }\end{array}$ & 0.019 & 1.19 & Enzyme \\
\hline Endothelin-1 & 0.002 & 0.79 & $\begin{array}{l}\text { Vascular } \\
\text { homestasis }\end{array}$ \\
\hline VPeptide YY & 0.010 & 0.79 & Hormone \\
\hline$\nabla$ Glucagon & 0.003 & 0.79 & Hormone \\
\hline Prolactin & 0.016 & 0.76 & Hormone \\
\hline $\begin{array}{l}\text { Monocyte chemotactic } \\
\text { protein } 5\end{array}$ & 0.003 & 0.73 & Immune response \\
\hline Apolipoprotein A1 & 0.001 & 0.73 & Lipid metabolism \\
\hline Osteopontin & 0.004 & 0.70 & Immune response \\
\hline VHaptoglobin & 0.014 & 0.70 & Immune response \\
\hline$\nabla$ Cystatin-C & 0.005 & 0.65 & $\begin{array}{l}\text { Protein } \\
\text { Metabolism }\end{array}$ \\
\hline$\nabla$ Stem cell factor & 0.004 & 0.63 & $\begin{array}{l}\text { Signal } \\
\text { transduction }\end{array}$ \\
\hline VFactor VII & 0.001 & 0.62 & Enzyme \\
\hline $\begin{array}{l}\text { Macrophage colony } \\
\text { stimulating factor } 1\end{array}$ & 0.001 & 0.59 & Cell differentiation \\
\hline VInterleukin-10 & 0.049 & 0.53 & Immune response \\
\hline$\nabla$ Epidermal growth factor & 0.002 & 0.51 & Growth factor \\
\hline $\begin{array}{l}\nabla \text { Vascular cellular } \\
\text { adhesion molecule } 1\end{array}$ & 0.001 & 0.48 & $\begin{array}{l}\text { Signal } \\
\text { transduction }\end{array}$ \\
\hline Beta 2 microglobulin & 0.031 & 0.48 & Immune response \\
\hline$\nabla$ Lymphotactin & 0.001 & 0.41 & Immune response \\
\hline
\end{tabular}

The ratio change was calculated as $d b / d b / c o n t r o l$. Functions were assigned using the Ingenuity Pathway Analysis Knowledge Base software as described in the Reseach Design and Methods section.

Increased and decreased levels of analytes are represented by green and red arrows respectively. 
Table 4 LC-MS ${ }^{E}$ analysis of frontal cortex from $d b / d b$ and control mice

\begin{tabular}{|c|c|c|c|c|c|}
\hline UniProt & Gene & Protein & Function & $\mathrm{P}$-value & Ratio \\
\hline$\triangle 088477$ & IF2B1 & $\begin{array}{l}\text { Insulin-like growth } \\
\text { factor } 2 \text { mRNA-binding } \\
\text { protein } 1\end{array}$ & Translation & 0.016 & 1.29 \\
\hline$\Delta P 11798$ & $K C C 2 A$ & $\begin{array}{l}\mathrm{Ca} 2+\text { calmodulin dep. } \\
\text { kinase type II } \alpha \text { chain }\end{array}$ & Kinase & 0.037 & 1.25 \\
\hline$\triangle Q 9 Z 2 Q 6$ & SEPT5 & Septin 5 & Enzyme & 0.035 & 1.24 \\
\hline$\triangle 089053$ & COR1A & Co & Oth & 0.030 & 1.16 \\
\hline$\nabla 008709$ & PRDX6 & doxin 6 & En & 0.035 & -1.10 \\
\hline VQ8K183 & PDXK & l kinase & Kina & 0.019 & -1.11 \\
\hline VP00920 & $\mathrm{CAH} 2$ & Carbonic anhydrase 2 & Enzyme & 0.038 & -1.13 \\
\hline VP63085 & MK01 & $\begin{array}{l}\text { Mitogen-activated } \\
\text { protein kinase } 1\end{array}$ & Kinase & 0.007 & -1.14 \\
\hline VQ02053 & UBA1 & $\begin{array}{l}\text { Ubiquitin-like modifier } \\
\text { activating enzyme } 1\end{array}$ & Enzyme & 0.036 & -1.14 \\
\hline$\nabla Q 61171$ & $P R D \times 2$ & Peroxiredoxin 2 & & & -1.16 \\
\hline & STMN2 & Stath & Other & & -1.19 \\
\hline$\nabla Q 61207$ & $S A P$ & Sulfated glycoprotein 1 & Other & 0.046 & -1.14 \\
\hline$\nabla P 06837$ & NEUM & Neuromodulin & Other & 0.009 & -1.18 \\
\hline
\end{tabular}

Abbreviations: LC-MS ${ }^{\mathrm{E}}$, liquid chromatography mass spectrometry; UniProt, UniProt accession code.

Cellular locations and molecular functions were assigned using Ingenuity Pathway Analysis Knowledge Base. The ratio was calculated as in the legend for Table 3.

Increased and decreased levels of analytes are represented by green and red arrows respectively.

$d b / d b$ mice peptide $Y Y$, glucagon, prolactin, apolipoprotein $\mathrm{A}$, monocyte chemotactic protein 5 , osteopontin, haptoglobin, interleukin 10, beta 2 microglobulin and lymphotactin.

Frontal cortex analysis. Brain proteome analyses of the $d b / d b$ and control mice were performed using $\mathrm{LC}-\mathrm{MS}^{\mathrm{E}}$ to determine whether changes occurred as described in some post-mortem studies of neuropsychiatric and neurodegenerative diseases. LC-MS ${ }^{\mathrm{E}}$ analysis of whole frontal cortex extracts led to the identification of 478 proteins. Of these proteins, 13 were found to be significantly altered in $d b / d b$ compared with control mice (Table 4). Four of these proteins were increased and nine decreased. The highest increase was observed for the insulin-like growth factor 2 mRNA binding protein 1 and the calcium calmodulin-dependent protein kinase type II alpha chain (CAMK2A). The most robust decreases were observed for stathmin 2 and neuromodulin. In silico functional analysis using the IPKB software analysis showed that 12 of the 13 altered proteins could be incorporated into a single interaction network (Figure 1). The top disease identified with the uploaded proteins was neurological disorder $(P=7.1 \mathrm{E}-5-4.4 \mathrm{E}-2)$ and Parkinson's disease-related signalling was the top canonical pathway ( $P=7.4 \mathrm{E}-5$; $2 / 16$ proteins).

Hippocampus analysis. Proteome analysis of the hippocampus from $d b / d b$ and control mice led to identification of 441 proteins. Differential analysis showed that more proteins were altered in this tissue compared with the frontal cortex, with 56 proteins found to be present at significantly different levels between $d b / d b$ and control mice (Table 5). The highest increases were observed for tubulin beta 5 chain and Thy 1 membrane glycoprotein. The largest decreases were found for groups of proteins involved in metabolic processes (malate dehydrogenase mitochondrial, cytochrome b c1 complex subunit 2, malate dehydrogenase cytoplasmic) or intracellular transport (alpha internexin, heat shock $70 \mathrm{kDa}$

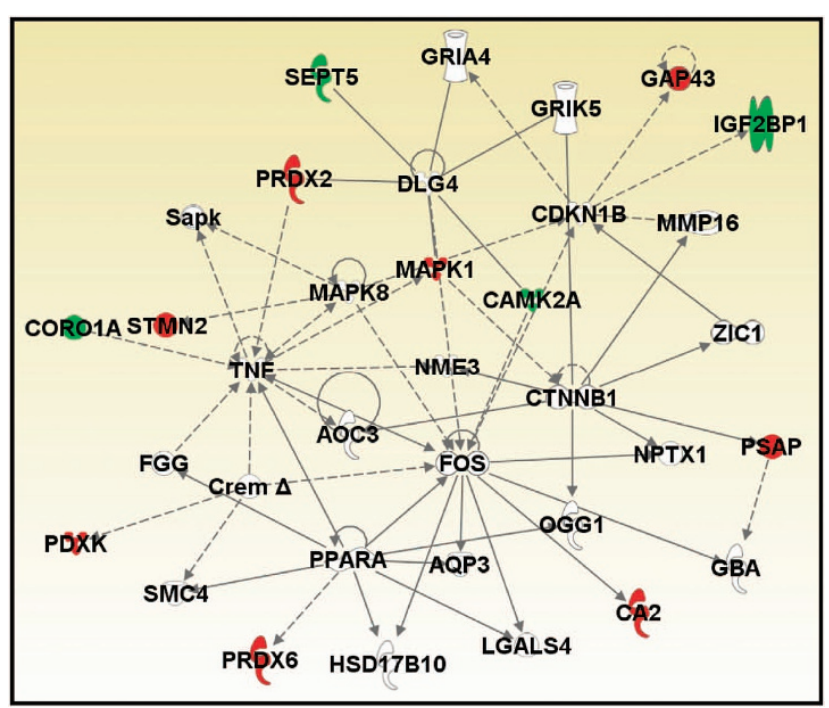

Figure 1 In silico functional analysis of proteomic changes in the frontal cortex of $d b / d b$ mice. UniProt accession codes were uploaded into the Ingenuity Pathway Analysis Knowledge Base to determine the most over-represented networks and canonoical pathways associated with the data. Straight lines = direct connections; dotted lines = indirect connections; green colour = increased; red colour $=$ decreased.

protein $1 \mathrm{~L}$, dihydropyrimidinase related protein 1 , ras-related protein rab 39B). IPKB analysis of the altered proteins identified a network comprising 14 of the target proteins (Figure 2). Most of the altered proteins were involved in cellular signalling, cell structure and maintenance, neural functioning and energy metabolism. Three members of the 14-3-3 protein family, conserved regulatory molecules expressed in all eukaryotes, were among the group of altered proteins. Furthermore, several molecules linked to regulation of calcium signalling were also altered. The top disease associated with the altered hippocampal proteins was hematological disease $(P=8.4 \mathrm{E}-5-1.7 \mathrm{E}-2)$ and the top canonical pathway was clathrin-mediated endocytosis signalling ( $P=3.0 \mathrm{E}-6 ; 7 / 181$ proteins).

\section{Discussion}

This is the first proteomic profiling study investigating plasma and brain tissues from the $d b / d b$ mouse model. The advantage of using the multiplex profiling approach is the potential to identify differences in hundreds of molecules simultaneously, which can lead to the identification of changes in functional pathways. Profiling of plasma from $d b / d b$ mice showed the expected robust increase in leptin levels, along with significantly higher levels of insulin compared with the levels in control mice. In line with these findings, we also found decreased levels of other hormones such as peptide $Y Y$, glucagon and prolactin, which suggested that lack of leptin receptors in the $d b / d b$ mice can lead to either altered biosynthesis or secretion of other major hormones.

The use of the multiplex immunoassay profiling analysis resulted in identification of several novel serum molecules, which have not been described previously in association with this model. The finding of lower peptide YY levels is consistent 
Table 5 LC-MS ${ }^{E}$ analysis of hippocampus from $d b / d b$ and control mice

\begin{tabular}{|c|c|c|c|c|c|}
\hline UniProt & Gene & Protein & Function & $\mathrm{P}$-value & Ratio \\
\hline$\triangle P 99024$ & TBB5 & Tubulin beta 5 chain & Other & 0.031 & 1.31 \\
\hline$\triangle P 01831$ & THY1 & Thy 1 membrane glycoprotein & Other & 0.032 & 1.29 \\
\hline P51881 & ADT2 & ADP ATP translocase 2 & Transporter & 0.007 & 1.26 \\
\hline$\triangle \mathrm{P} 68033$ & ACTC & Actin alpha cardiac muscle 1 & Enzyme & 0.046 & 1.26 \\
\hline$\triangle \mathrm{Q9R0K7}$ & AT2B2 & Plasma membrane calcium transporting ATPase 2 & Transporter & 0.005 & 1.25 \\
\hline$\Delta$ P11499 & HS90B & Heat-shock protein HSP 90 & Other & 0.006 & 1.21 \\
\hline Q80W21 & GSTM7 & Glutathione S transferase Mu 7 & Enzyme & 0.041 & 1.18 \\
\hline$\triangle$ Q9D0J8 & PTMS & Parathymosin & Other & 0.030 & 1.15 \\
\hline QQ6SS7 & $\mathrm{H} 2 \mathrm{~A} 2 \mathrm{~A}$ & Histone H2A type 2 A & Other & 0.031 & 1.14 \\
\hline P02088 & HBB1 & Hemoglobin subunit beta 1 & Transporter & 0.002 & 1.14 \\
\hline$\triangle \mathrm{P} 68254$ & $1433 \mathrm{~T}$ & 1433 protein theta & Other & 0.002 & 1.14 \\
\hline$\triangle$ Q9D6F9 & TBB4A & Tubulin beta 4 chain & Other & 0.019 & 1.13 \\
\hline$\triangle Q 99 L X 0$ & PARK & Protein DJ 1 & Enzyme & 0.026 & 1.12 \\
\hline$\triangle P 20029$ & GRP78 & $78 \mathrm{kDa}$ glucose-regulated protein & Other & 0.002 & 1.11 \\
\hline$\triangle \mathrm{P} 00920$ & $\mathrm{CAH} 2$ & Carbonic anhydrase 2 & Enzyme & 0.030 & 1.10 \\
\hline$\triangle \mathrm{Q} 6 \mathrm{PHZ2}$ & KCC2D & $\mathrm{Ca} 2+$ calmodulin dep protein kinase type $\| \Delta$ chain & Kinase & 0.019 & 1.10 \\
\hline P63268 & ACTH & Actin gamma enteric smooth muscle & Other & 0.026 & 1.10 \\
\hline$\Delta \mathrm{P} 17183$ & ENOG & Gamma enolase & Enzyme & 0.040 & 1.10 \\
\hline$\nabla 035660$ & GSTM6 & Glutathione S transferase Mu 6 & Enzyme & 0.001 & -1.10 \\
\hline VP70696 & H2B1A & Histone $\mathrm{H} 2 \mathrm{~B}$ type $1 \mathrm{~A}$ & Other & 0.042 & -1.10 \\
\hline VQ61990 & PCBP2 & Poly rC binding protein 2 & Other & 0.007 & -1.10 \\
\hline VP15532 & NDKA & Nucleoside diphosphate kinase A & Kinase & 0.030 & -1.11 \\
\hline VP28184 & MT3 & Metallothionein 3 & Other & 0.038 & -1.12 \\
\hline VQ9D1G1 & RAB1B & Ras related protein Rab 1B & Enzyme & 0.001 & -1.12 \\
\hline$\nabla P 09041$ & PGK2 & Phosphoglycerate kinase 2 & Kinase & 0.026 & -1.13 \\
\hline$\nabla 070456$ & 14335 & 1433 protein sigma & Other & 0.024 & -1.13 \\
\hline VP21550 & ENOB & Beta enolase & Enzyme & 0.009 & -1.13 \\
\hline$\nabla Q 62420$ & SH3G2 & Endophilin A1 & Enzyme & 0.045 & -1.13 \\
\hline$\nabla P 08553$ & NFM & Neurofilament medium polypeptide & Other & 0.012 & -1.14 \\
\hline VP62827 & RAN & GTP-binding nuclear protein Ran & Enzyme & 0.019 & -1.14 \\
\hline$\nabla Q 63810$ & CANB1 & Calcineurin subunit $B$ type 1 & Phosphatase & 0.035 & -1.15 \\
\hline VQ9WV27 & AT1A4 & $\mathrm{Na}+/ \mathrm{K}+$ transporting ATPase subunit alpha 4 & Transporter & 0.035 & -1.17 \\
\hline VP06837 & NEUM & Neuromodulin & Other & 0.012 & -1.18 \\
\hline VQ61598 & GDIB & Rab GDP dissociation inhibitor beta & Other & 0.012 & -1.18 \\
\hline VQ9CQV8 & $1433 \mathrm{~B}$ & 1433 protein alpha & Other & 0.019 & -1.18 \\
\hline VP31001 & DESM & Desmin & Other & 0.019 & -1.19 \\
\hline VP31786 & ACBP & Acyl CoA-binding protein & Other & 0.046 & -1.19 \\
\hline VP26443 & DHE3 & Glutamate dehydrogenase 1 mitochondrial & Enzyme & 0.023 & -1.19 \\
\hline VP28652 & KCC2B & $\mathrm{Ca} 2+$ calmodulin dep protein kinase type II Bchain & Kinase & 0.046 & -1.20 \\
\hline VQ9R0P9 & UCHL1 & Ubiquitin carboxyl terminal hydrolase isozyme L1 & Peptidase & 0.017 & -1.21 \\
\hline VP05202 & AATM & Aspartate aminotransferase mitochondrial & Enzyme & 0.001 & -1.21 \\
\hline VP63328 & PP2BA & Ser/Thr protein phosphatase $2 \mathrm{~B}$ catalytic subunit $\alpha$ & Phosphatase & 0.004 & -1.22 \\
\hline$\nabla Q 01768$ & NDKB & Nucleoside diphosphate kinase B & Kinase & 0.047 & -1.22 \\
\hline$\nabla 035737$ & $\mathrm{HNRH} 1$ & Heterogeneous nuclear ribonucleoprotein $\mathrm{H}$ & Other & 0.014 & -1.23 \\
\hline VP50516 & VATA & V-type proton ATPase catalytic subunit A & Transporter & 0.030 & -1.23 \\
\hline VQ8BHC1 & RB39B & Ras related protein Rab 39B & Enzyme & 0.004 & -1.24 \\
\hline VP09671 & SODM & Superoxide dismutase $\mathrm{Mn}$ mitochondrial & Enzyme & 0.017 & -1.26 \\
\hline$\nabla 008709$ & PRDX6 & Peroxiredoxin 6 & Enzyme & 0.035 & -1.28 \\
\hline VP02104 & HBE & Hemoglobin subunit epsilon Y2 & Transporter & 0.030 & -1.29 \\
\hline VP61750 & ARF4 & ADP ribosylation factor 4 & Enzyme & 0.012 & -1.30 \\
\hline VP46660 & AINX & Alpha internexin & Other & 0.004 & -1.32 \\
\hline VP16627 & HS71L & Heat shock $70 \mathrm{kDa}$ protein $1 \mathrm{I}$ & Other & 0.023 & -1.38 \\
\hline VP97427 & DPYL1 & Dihydropyrimidinase related protein 1 & Enzyme & 0.009 & -1.45 \\
\hline VP08249 & MDHM & Malate dehydrogenase mitochondrial & Enzyme & 0.005 & -1.45 \\
\hline VQ9DB77 & QCR2 & Cytochrome b c1 complex subunit 2 mitochondrial & Enzyme & 0.030 & -1.47 \\
\hline VP14152 & $\mathrm{MDHC}$ & Malate dehydrogenase cytoplasmic & Enzyme & 0.003 & -1.47 \\
\hline
\end{tabular}

Abbreviations: LC-MSE ${ }^{\mathrm{E}}$, liquid chromatography mass spectrometry; UniProt, UniProt accession code.

Cellular locations and molecular functions were assigned using Ingenuity Pathway Analysis Knowledge Base. The ratio was calculated as in the legend for Table 3. Increased and decreased levels of analytes are represented by green and red arrows respectively.

with the increased appetite and body weight of the $d b / d b$ mice and with previous studies which have shown that obese humans secrete lower levels of this hormone. ${ }^{19}$ Lower levels of peptide $Y Y$ have also been found in drug-free schizophrenia patients in a biomarker study of cerebrospinal fluid, suggesting another link between metabolic regulation and psychiatric disorders. ${ }^{20}$ The finding of decreased circulating prolactin levels in $d b / d b$ mice has also not been reported previously. Prolactin is secreted by the anterior pituitary and this process can be inhibited by release of dopamine from the arcuate nuclease of the hypothalamus. ${ }^{21}$ This is interesting as one of the major theories of how schizophrenia develops involves increased dopaminergic activity in the brain. ${ }^{22}$ Therefore, further studies are warranted to determine whether hypothalamic-pituitary dopamine signalling is altered in this model.

In addition to the effects on hormonal pathways, we also identified alterations in immune and inflammation-related molecules in plasma from $d b / d b$ mice. Several studies 


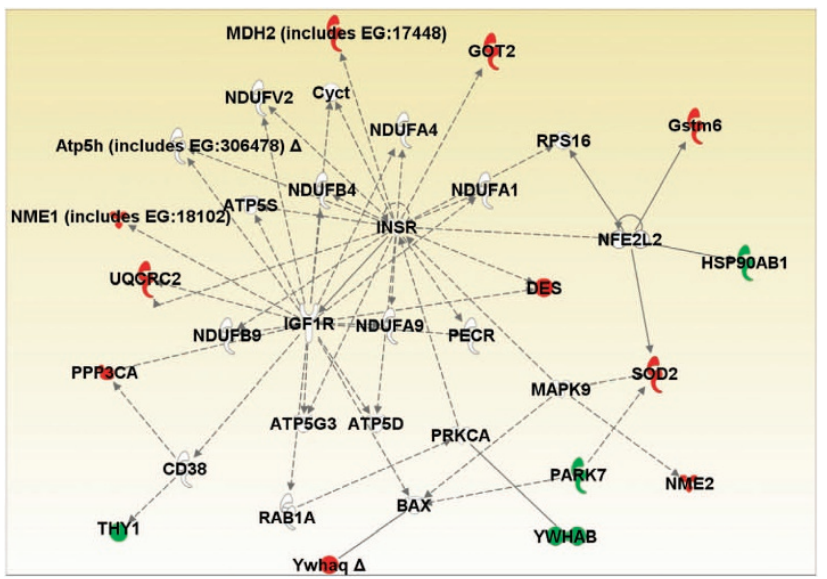

Figure 2 In silico functional analysis of protein changes in the hippocampus of $d b / d b$ mice. UniProt accession codes were uploaded into the Ingenuity Pathway Analysis Knowledge Base to determine the most over-represented networks and canonoical pathways associated with the data. Straight lines $=$ direct connections; dotted lines $=$ indirect connections; green colour = increased; red colour $=$ decreased.

have shown that immune system perturbations occur in type 2 diabetes mellitus, ${ }^{23}$ as well as in psychiatric and neurodegenerative disorders, including schizophrenia, ${ }^{17}$ depression $^{24}$ and Alzheimer's disease. ${ }^{25}$ However, the overlap of immune-related molecules across these conditions with the $d b / d b$ mice model is not surprising given that these pathways are affected in a variety of diseases. In the case of the $d b / d b$ mouse, the observed perturbations in immune system molecules could be due to the high circulating levels of leptin, as this hormone can also act as pro-inflammatory adipokine. ${ }^{26}$ Leptin has been tested as a possible treatment for autoimmune and/or inflammatory diseases in a recent study $^{27}$ and preclinical studies have shown that the depression-like symptoms in the chronic stress and social defeat rat models was associated with lower serum leptin concentrations, and the behavioral effects could be reversed by systemic leptin administration. ${ }^{28}$

Comparison of circulating molecules changing in the $d b / d b$ mouse model to those identified in our previous study of first onset schizophrenia patients shows that 12 proteins were altered in common and 6 of these showed the same directional changes (insulin, serum amyloid $P$, interleukin 18 , serum glutamic-oxaloacetic transaminase, apolipoprotein A1 and epidermal growth factor). ${ }^{17}$ In addition, seven circulating proteins (insulin, serum glutamic-oxaloacetic transaminase, prolactin, cystatin $\mathrm{C}$, stem cell factor, macrophage colony-stimulating factor and beta-2 microglobulin) were changed in common between the $d b / d b$ mouse and the acute PCP rat model of schizophrenia, using the same molecular profiling platform. ${ }^{29}$ Taken together, these findings suggest that the $d b / d b$ model shows an overlap of molecular profiles with schizophrenia and other psychiatric or neurodegenerative disorders.

The most novel findings of the current study involved the identification of changes in brain proteins as these have not been described previously in association with this model. Consistent with the effects on behavior seen in the $d b / d b$ mice ${ }^{13,14}$ we identified multiple proteins that were altered in brain tissues extracted from $d b / d b$ mice compared with control mice. The finding that more proteins were altered in the hippocampus of the $d b / d b$ mouse is consistent with the reported effects on cognition and learning in this model. In line with this, we found changes in three members of the 14-3-3 protein family in $d b / d b$ mouse hippocampi. These proteins are highly conserved and have an important role in neurodevelopment due to their involvement in cellular processes, such as cell signalling, growth and apoptosis. ${ }^{30}$ Also, perturbations in these proteins have been found in schizophrenia, autism, bipolar disorder and in subjects with impaired sensory motor gating and memory. ${ }^{30,31}$ The latter finding is consistent with the impairments seen in paired-pulse inhibition in the $d b / d b$ mice. Furthermore, our findings of altered expression of $\mathrm{Ca}^{2+}$-regulatory proteins, such as CAMK2B, CAMK2D and calcineurin subunit B type 1 , are in line with studies that identified impaired cardiac function in $d b / d b$ mice through suppression of $\mathrm{Ca}^{2+}$ permeability. ${ }^{32}$ This also supports the possibility that the defect found in the $d b / d b$ mice is systemic, with effects seen in both the brain and periphery.

Fewer proteomic changes were found in the frontal cortex region of the $d b / d b$ mice using the LC-MS ${ }^{\mathrm{E}}$ proteomic profiling approach. However, in silico analysis of the 13 significantly altered proteins resulted in identification of 'neurological disorder' as the top associated disease and 'Parkinson's signalling' as the top canonical pathway. Again, this indicated potential effects on dopaminergic pathways as seen most notably in Parkinson's disease and schizophrenia. In addition, one of the brain proteins found to be altered in both the $d b / d b$ and the acute PCP rodent model described above, ${ }^{29}$ was protein DJ-1 (also known as PARK7). DJ-1 is an oxidative stress response protein that defends cells against reactive oxygen species. Furthermore, CAMK2A was found to be changing in the $d b / d b$ mice as found in our previous study of the acute PCP model of schizophrenia. ${ }^{29}$ Previous studies have also found perturbed expression of these proteins in post-mortem frontal cortex tissues from schizophrenia patients ${ }^{33,34}$ as well as in disorders associated with effects on learning and memory. ${ }^{35-37}$

One limitation of this study was the small numbers of animals used to generate the data. However, we have attempted to compensate for this through comparison of the findings with those in the literature on the same mouse model, the acute PCP model, drug-naive schizophrenia subjects and on protein pathways altered in schizophrenia post-mortem brain tissues. Nevertheless, these studies require repetition in independent cohorts of $d b / d b$ mice, and future studies should attempt to further explore the specificity of the effects through comparison with other animal models and other human psychiatric and neurodegenerative diseases. Also, the $d b / d b$ mouse has been mainly used in type 2 diabetes research, and it should be noted that the alterations in central nervous system could result from the change of leptin receptor signalling in the brain or though complications of diabetes itself.

In conclusion, this study resulted in the identification of novel central nervous system proteomic alterations that link the metabolic abnormalities found in the $d b / d b$ mouse model to neurodegenerative and neuropsychiatric diseases. 
This has laid the ground work for further studies of the $d b / d b$ mouse model in testing whether treatment with drugs such as antidepressants, antipsychotics or anti-diabetic compounds has a positive effect on the behaviors and brain proteome changes observed. Sharma et al. ${ }^{14}$ have already carried out a study which showed that treatment of $d b / d b$ mice with rosiglitazone could affect depression measures, but this had no effect on readouts for psychosis-like behaviours. Taken together with previous investigations on the behavioural effects in this model, the current study supports the use of the $d b / d b$ mouse as a potential preclinical model for schizophrenia and potentially other psychiatric or neurodegenerative disorders. Also, the combined use of this model with incorporation of high throughput assays for the plasma and brain molecular candidates identified here would potentially offer a useful novel tool for drug discovery, with a focus on the metabolic aspects of mental disorders and/or the psychopathology associated with diabetes.

\section{Conflict of interest}

SB, HR and PCG are consultants for Myriad-RBM, although this does not alter adherence to Translational Psychiatry policies on sharing data and materials. The other authors declare no conflict of interest.

Acknowledgements. The research leading to these results has received funding from the Stanley Medical Research Institute, the Dutch Fund for Economic Structure Reinforcement (FES), under grant agreement number 0908 (NeuroBasic PharmaPhenomics project), the American Heart Association Grant SDG 0735112N and the National Institutes of Health Grant R01 HL093567. The mass spectrometry work was MIAPE-compliant. SB is the guarantor of this work and, as such, had full access to all the data in the study and takes responsibility for the integrity of the data and the accuracy of the data analysis.

1. Kaidanovich-Beilin O, Cha DS, McIntyre RS. Crosstalk between metabolic and neuropsychiatric disorders. F1000 Biol Rep 2012; 4: 14.

2. Meyer JM, Davis VG, Goff DC, McEvoy JP, Nasrallah HA, Davis SM et al. Change in metabolic syndrome parameters with antipsychotic treatment in the CATIE Schizophrenia Trial: prospective data from phase 1. Schizophr Res 2008; 101: 273-286.

3. Ryan MC, Collins $P$, Thakore $\mathrm{JH}$. Impaired fasting glucose tolerance in first-episode, drugnaive patients with schizophrenia. Am J Psychiatry 2008; 160: 284-289.

4. Guest PC, Wang L, Harris LW, Burling K, Levin Y, Ernst A et al. Increased levels of circulating insulin-related peptides in first-onset, antipsychotic naive schizophrenia patients. Mol Psychiatry 2010; 15: 118-119.

5. Kobayashi K, Forte TM, Taniguchi S, Ishida BY, Oka K, Chan L. The db/db mouse, a model for diabetic dyslipidemia: molecular characterization and effects of Western diet feeding. Metabolism 2000; 49: 22-31.

6. Hummel KP, Dickie MM, Coleman DL. Diabetes, a new mutation in the mouse. Science 1966; 153: 1127-1128

7. Coleman DL. A historical perspective on leptin. Nat Med 2010; 16: 1097-1099

8. Dinel AL, Andre C, Aubert A, Ferreira G, Laye S, Castanon N. Cognitive and emotional alterations are related to hippocampal inflammation in a mouse model of metabolic syndrome. PLoS One 2011; 6: e24325.

9. Anderson RJ, Freedland KE, Clouse RE, Lustman PJ. The prevalence of comorbid depression in adults with diabetes: a meta-analysis. Diabetes Care 2001; 24: 1069-1078.

10. Arvanitakis Z, Wilson RS, Bienias JL, Evans DA, Bennett DA. Diabetes mellitus and risk of Alzheimer disease and decline in cognitive function. Arch Neurol 2004; 61: 661-666.

11. Gotz J, Ittner LM, Lim YA. Common features between diabetes mellitus and Alzheimer's disease. Cell Mol Life Sci 2009; 66: 1321-1325.
12. Li XL, Aou S, Oomura Y, Hori N, Fukunaga K, Hori T. Impairment of long-term potentiation and spatial memory in leptin receptor-deficient rodents. Neuroscience 2002; 113: 607-615.

13. Sharma AN, Elased KM, Garrett TL, Lucot JB. Neurobehavioral deficits in db/db diabetic mice. Physiol Behav. 2010; 101: 381-388.

14. Sharma AN, Elased KM, Lucot JB. Rosiglitazone treatment reversed depression- but not psychosis-like behavior of db/db diabetic mice. J Psychopharmacol 2012; 26: 724-732.

15. Trayhurn $P$. Thermoregulation in the diabetic-obese $(\mathrm{db} / \mathrm{db})$ mouse. The role of nonshivering thermogenesis in energy balance. Pflugers Arch 1979; 380: 227-232.

16. Taicher GZ, Tinsley FC, Reiderman A, Heiman ML. Quantitative magnetic resonance (QMR) method for bone and whole-body-composition analysis. Anal Bioanal Chem 2003; 377: 990-1002.

17. Schwarz E, Guest PC, Rahmoune H, Harris LW, Wang L, Leweke FM et al. Identification of a biological signature for schizophrenia in serum. Mol Psychiatry 2012; 17: 494-502.

18. Krishnamurthy D, Levin Y, Harris LW, Umrania Y, Bahn S, Guest PC. Analysis of the human pituitary proteome by data independent label-free liquid chromatography tandem mass spectrometry. Proteomics 2011; 11: 495-500.

19. Ie Roux CW, Bloom SR. Peptide YY, appetite and food intake. Proc Nutr Soc 2005; 64 213-216.

20. Widerlov E, Lindstrom LH, Wahlestedt C, Ekman R. Neuropeptide $Y$ and peptide $Y Y$ as possible cerebrospinal fluid markers for major depression and schizophrenia, respectively. J Psychiatr Res 1988; 22: 69-79.

21. Benker G, Jaspers C, Hausler G, Reinwein D. Control of prolactin secretion. Klin Wochenschr 1990; 68: 1157-1167.

22. Carlton PL, Manowitz P. Dopamine and schizophrenia: an analysis of the theory. Neurosci Biobehav Rev 1984; 8: 137-151.

23. Pickup JC, Crook MA. Is type II diabetes mellitus a disease of the innate immune system? Diabetologia 1998; 41: 1241-1248.

24. Krishnadas R, Cavanagh J. Depression: an inflammatory illness? J Neurol Neurosurg Psychiatry 2012; 83: 495-502.

25. Singh VK. Studies of neuroimmune markers in Alzheimer's disease. Mol Neurobiol 1994; 9 : 73-81.

26. Stofkova A. Leptin and adiponectin: from energy and metabolic dysbalance to inflammation and autoimmunity. Endocr Regul 2009; 43: 157-168.

27. Fantuzzi G, Faggioni R. Leptin in the regulation of immunity, inflammation, and hematopoiesis. J Leukoc Biol 2000; 68: 437-446.

28. Lu XY, Kim CS, Frazer A, Zhang W. Leptin: a potential novel antidepressant. Proc Nat Acad Sci USA. 2006; 103: 1593-1598.

29. Ernst A, Ma D, Garcia-Perez I, Tsang TM, Kluge W, Schwarz E et al. Molecular validation of the acute phencyclidine rat model for schizophrenia: identification of translational changes in energy metabolism and neurotransmission. J Proteome Res 2012; 11: 3704-3714.

30. Jia $Y, Y u X$, Zhang B, Yuan Y, Xu Q, Shen Y. An association study between polymorphisms in three genes of 14-3-3 (tyrosine 3-monooxygenase/tryptophan 5-monooxygenase activation protein) family and paranoid schizophrenia in northern Chinese population. Eur Psychiatry 2004; 19: 377-379.

31. Cheah PS, Ramshaw HS, Thomas PQ, Toyo-Oka K, Xu X, Martin S et al. Neurodevelopmental and neuropsychiatric behaviour defects arise from 14-3-3zeta deficiency. Mol Psychiatry 2012; 17: 451-466.

32. Pereira L, Matthes J, Schuster I, Valdivia HH, Herzig S, Richard S et al. Mechanisms of $[\mathrm{Ca} 2+] \mathrm{i}$ transient decrease in cardiomyopathy of $\mathrm{db} / \mathrm{db}$ type 2 diabetic mice. Diabetes 2006; 55: 608-615

33. Kilarski LL, Pearson JP, Newsway V, Majounie E, Knipe MD, Misbahuddin A et al. Systematic review and UK-based study of PARK2 (parkin), PINK1, PARK7 (DJ-1) and LRRK2 in early-onset Parkinson's disease. Mov Disord 2012; 27: 1522-1529.

34. Morishita T, Hidaka T, Sugahara K, Noguchi T. Leptin changes Ca2 +/calmodulindependent response and up-regulates the gene expression of calcineurin in rat hypothalamus. Life Sci 1998; 63: PL311-PL315.

35. Govoni S, Amadio M, Battaini F, Pascale A. Senescence of the brain: focus on cognitive kinases. Curr Pharm Des 2010; 16: 660-671.

36. Mizuno K, Giese KP. Hippocampus-dependent memory formation: do memory typespecific mechanisms exist? J Pharmacol Sci 2005; 98: 191-197.

37. Novak G, Seeman P, Tallerico T. Increased expression of calcium/calmodulin-dependent protein kinase Ilbeta in frontal cortex in schizophrenia and depression. Synapse 2006; 59 : 61-68.

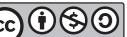

Translational Psychiatry is an open-access journal published by Nature Publishing Group. This work is licensed under a Creative Commons Attribution-NonCommercialShareAlike 3.0 Unported License. To view a copy of this license, visit http://creativecommons.org/licenses/by-nc-sa/3.0/ 